This article was downloaded by: [CAS Consortium]

On: 5 May 2009

Access details: Access Details: [subscription number 909168890]

Publisher Taylor \& Francis

Informa Ltd Registered in England and Wales Registered Number: 1072954 Registered office: Mortimer House, 37-41 Mortimer Street, London W1T 3JH, UK

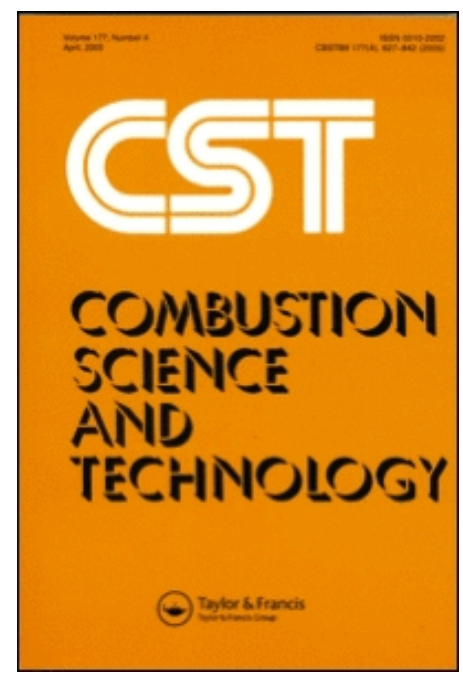

Combustion Science and Technology

Publication details, including instructions for authors and subscription information:

http://www.informaworld.com/smpp/title content=t713456315

\title{
Experimental Investigation on Flameholding Mechanism and Combustion Performance in Hydrogen-Fueled Supersonic Combustors
}

\section{G. Yu a; J. G. Li a; X. Y. Zhang a; L. H. Chen a; B. Han b; C. J. Sung ${ }^{b}$}

a Laboratory of High Temperature Gas Dynamics, Institute of Mechanics, Chinese Academy of Sciences, Beijing, People's Republic of China. ${ }^{b}$ Department of Mechanical and Aerospace Engineering, Case Western Reserve University, Cleveland, Ohio, USA.

Online Publication Date: 01 March 2002

To cite this Article Yu, G., Li, J. G., Zhang, X. Y., Chen, L. H., Han, B. and Sung, C. J.(2002)'Experimental Investigation on Flameholding Mechanism and Combustion Performance in Hydrogen-Fueled Supersonic Combustors',Combustion Science and Technology, 174:3,1 - 27

To link to this Article: DOI: $10.1080 / 713712992$

URL: http://dx.doi.org/10.1080/713712992

\section{PLEASE SCROLL DOWN FOR ARTICLE}

Full terms and conditions of use: http://www.informaworld.com/terms-and-conditions-of-access.pdf

This article may be used for research, teaching and private study purposes. Any substantial or systematic reproduction, re-distribution, re-selling, loan or sub-licensing, systematic supply or distribution in any form to anyone is expressly forbidden.

The publisher does not give any warranty express or implied or make any representation that the contents will be complete or accurate or up to date. The accuracy of any instructions, formulae and drug doses should be independently verified with primary sources. The publisher shall not be liable for any loss, actions, claims, proceedings, demand or costs or damages whatsoever or howsoever caused arising directly or indirectly in connection with or arising out of the use of this material. 


\title{
EXPERIMENTAL INVESTIGATION ON FLAMEHOLDING MECHANISM AND COMBUSTION PERFORMANCE IN HYDROGEN-FUELED SUPERSONIC COMBUSTORS
}

\author{
G. YU, J. G. LI, X. Y. ZHANG, AND L. H. CHEN \\ Laboratory of High Temperature Gas Dynamics, \\ Institute of Mechanics, Chinese Academy of Sciences, \\ Beijing, People's Republic of China
}

\author{
B. HAN AND C. J. SUNG* \\ Department of Mechanical and Aerospace Engineering, \\ Case Western Reserve University, Cleveland, Ohio, USA
}

\begin{abstract}
Supersonic $\mathrm{H}_{2}$ /air combustion experiments of a fixed entry Mach number 2.5 were conducted using eight different model combustors, at various stagnation conditions and global equivalence ratios. Specifically, stagnation temperature varied from 1200 to $2000 \mathrm{~K}$, stagnation pressure ranged from 1 to $1.4 \mathrm{MPa}$, and the global equivalence ratio covered the range from lean to rich. In addition, the static pressure distribution in the axial direction and total pressure at the combustor exit were measured. Effects of wall injection, strut injection, and cavity flameholder were systematically investigated and compared. A one-dimensional model was further applied for data reduction and
\end{abstract}

Received 6 December 2000; accepted 12 February 2002.

The research program of the Chinese Academy of Sciences was jointly supported by the National Natural Science Foundation of China and the Expert Committee of Aerospace Technology, Area of National 863, Program of China through the contract 863-2-2-30-3. CJS was supported by the Case School of Engineering through the Case Alumni Association. BH would also like to acknowledge fellowship support by the Case School of Engineering.

*Address correspondence to cjs15@po.cwru.edu 
analysis. The calculated results were found to be fairly consistent with the experimental measurements. Performances of various model combustors, as well as the factors affecting combustion efficiency and total pressure recovery, were discussed.

Keywords: supersonic combustion, flame stabilization

\section{INTRODUCTION}

An essential element in the successful development of supersonic propulsion devices is the concomitant design of the supersonic combustor. Since flows within these combustors are supersonic, the mixing time and residence time available for reaction are drastically reduced compared to situations within subsonic combustors. Recognizing that the feasibility of hypersonic propulsion largely depends on the combustion efficiency in the scramjet combustor and that the efficiency is critically related to the degree of fuel-air mixing as well as the bulk flame stabilization, the present investigation aimed to study experimentally the enhancement of overall mixing and flame stabilization in hydrogen-air supersonic combustion using various model combustors. The motivation for the present efforts follows.

The flow within the practical scramjet combustor is extremely complex and hence is obviously quite different from that employed in most fundamental mixing enhancement studies. For example, the influences of the shock waves within the inlet and isolator, as well as the associated thick turbulent boundary layer, will inevitably extend to the combustor. Such influences can subsequently lead to the interactions of a shock-mixing layer and shock-boundary layer inside the combustor. While the shockmixing layer interactions may enhance the overall mixing rate (Marble, 1990), the shock-boundary layer interactions may induce boundary layer separation and hence form a low-speed recirculation flow (Shapiro, 1953). Obviously, the induced boundary layer separation would cause problems for most hypermixer fuel injectors mounted on the combustor wall, since the local flow is preferred to be supersonic without separation (Drummond, 1991).

Due to the very limited residence time available within the combustor, extensive studies have been conducted to explore various approaches in achieving complete combustion of the reactants (Billig, 1993). One major methodology for active flame stabilization is to create a local region of slow flow velocity and possibly high chemical reactivity so that the flame 
segment in this region anchors the bulk flame. Frequently, this mode of stabilization is closely coupled to the fuel injection processes such as parallel, angled, and normal injection. Although parallel injection is advantageous in terms of fuel momentum addition, its inefficient mixing is a well-known shortcoming. Such inefficiency can be overcome by using a normal injection scheme. However, normal injection can induce a detached normal shock wave together with the associated boundary layer separation, which would lead to severe local loss of total pressure and result in a decrease in overall cycle efficiency.

Through the research of scramjet engine performance, Bushnell (1994) pointed out that for Mach numbers ranging from 6 to 12, a transverse injector can be utilized to provide appreciable mixing enhancement and produce adequate thrust margin. Therefore, one thrust of the present investigation emphasized the use of the transverse injection. In addition, a straightforward way to enhance mixing is to reduce the mixing gap by placing struts within the combustor, which would be a promising approach to meet the requirements of scramjet overall cycle efficiency.

Furthermore, it is well known that combustor configuration can significantly affect the self-ignition characteristics and flame stabilization capability. For instance, recent scramjet studies (Yu et al., 1998; Baurl and Gruber, 1998; Ben-Yakar and Hanson, 1999) have demonstrated that cavities are quite effective as self-ignition and flameholding devices. Therefore, it is imperative to conduct a systematic and comprehensive investigation to illustrate several optimal configurations, which would lead to effective flameholding capability with minimal total pressure loss.

In view of the above considerations, the objectives of the present study were three fold. The first was to extend our previous efforts on in-stream strut injection ( $\mathrm{Li}$ et al., 1997) to include the use of wall injection and their combination, with emphasis on comparing the mixing characteristics and combustion efficiencies of various combustors. Second, for a given fuel injection design, the influence of combustor geometry on the thermal choking tendency was investigated, particularly the effects due to the length of the constant-area section and the expansion angle of the divergent section. Third, the effects due to the inclusion of cavity flameholders on the combustion characteristics were investigated. Performances of various model combustors designed herein were also systematically tested and assessed. Experimental results were then analyzed with a simplified, one-dimensional model. Through the present experimental and modeling explorations, it was hoped that the optimum 
conditions for mixing, flameholding, and combustion efficiency can be determined via the combined utilization of multi-orifice wall injections, in-stream struts, and cavity flameholders.

We shall sequentially present the supersonic combustion facility employed herein, experimental methodologies, experimental results, and the associated discussion. An Appendix delineates the simplified onedimensional model used for data reduction and analysis.

\section{EXPERIMENTAL CONSIDERATIONS}

\section{Supersonic Combustion Facility}

Details of the test facility have been described elsewhere (Yu et al., 1996; Li et al., 1997; Yu et al., 1998). Highlights of some important characteristics are as follows. High temperature vitiated test air was produced by burning hydrogen, oxygen, and air in a heater, with the resulting oxygen volume fraction equal to that of normal air. The heater can provide vitiated air up to its maximum capability with a temperature of $2100 \mathrm{~K}$, a pressure of $4.5 \mathrm{MPa}$, and a mass flow rate of $2.0 \mathrm{~kg} / \mathrm{s}$. An improvement to the previous facility was to enlarge test channel area to $51 \mathrm{~mm} \times 70 \mathrm{~mm}$. Figure 1 shows the schematic of experimental setup. All the flow rates were metered by sonic nozzles. The uncertainty associated with the flow rate measurement was estimated to be within $3 \%$.

There were eight types of supersonic combustors designed and tested, which are sketched in Figure 2. In all cases, the nominal Mach number at the combustor entrance was 2.5 , which was produced by a twodimensional nozzle. This combustor entrance condition basically simulates a flight speed of Mach 6.6 (Heiser and Pratt, 1994). For the cases with normal injection on the combustor wall, there were rows of 16 orifices, which were $1.6 \mathrm{~mm}$ in diameter and $4 \mathrm{~mm}$ apart. For the cases with strut injection, there were 11 orifices of $1.1 \mathrm{~mm}$ in diameter and $5 \mathrm{~mm}$ in spacing along the upper and lower sides of the strut so that the total injection area was kept the same as that of the wall injection runs. In addition, the strut was made of stainless steel with thickness of $8 \mathrm{~mm}$ and 30-degree back-sweeping (cf. Figure 2) in order to avoid severe loss of the total pressure. Each cavity, when used, was of $10 \mathrm{~mm}$ in depth, $30 \mathrm{~mm}$ in length, and 45 degrees in aft ramp angle, as shown in Figure 2.

For clarity, the configurations of eight different model combustors are outlined as follows: 


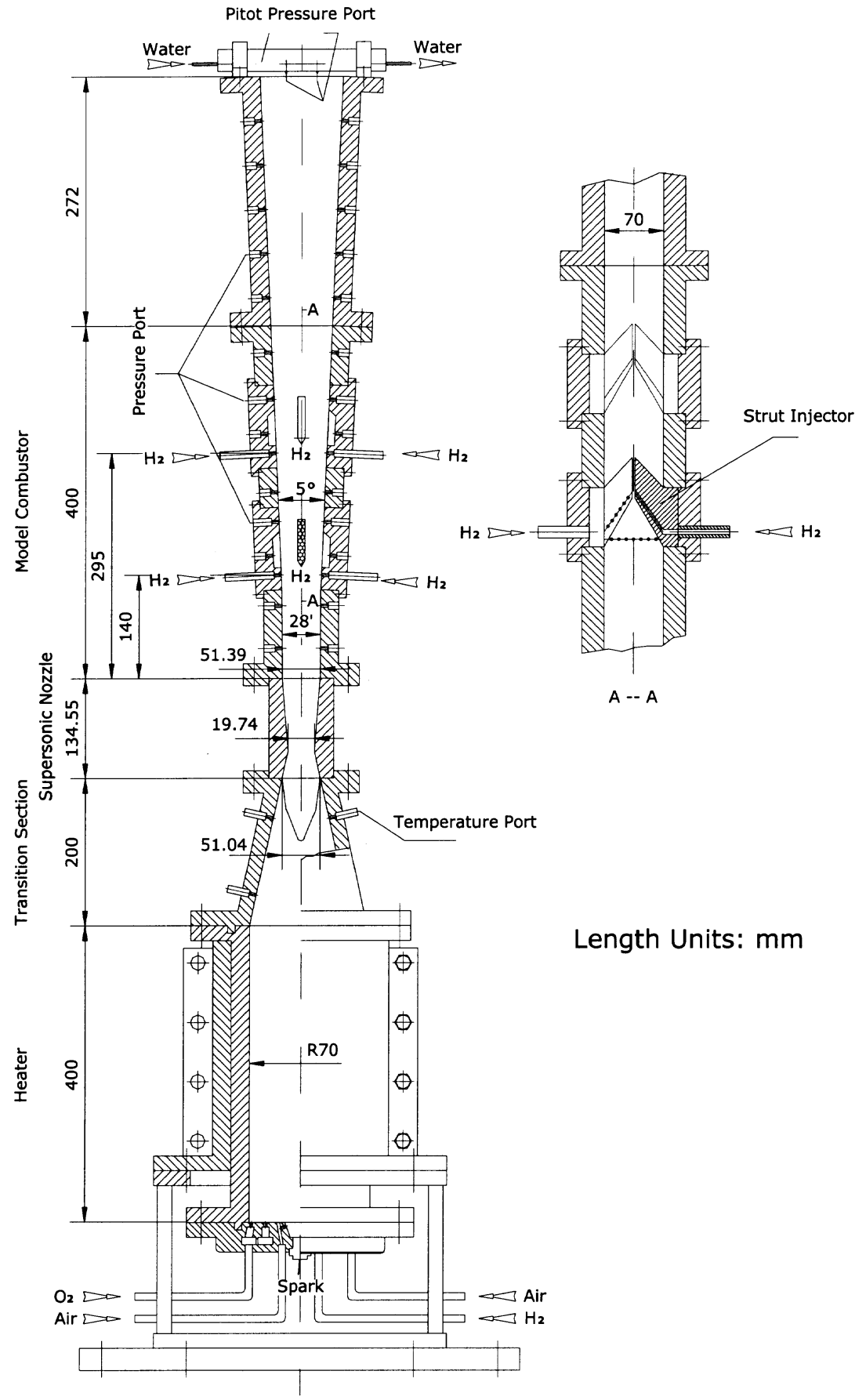

Figure 1. Schematic of experimental facility. 
Combustor Model No.1

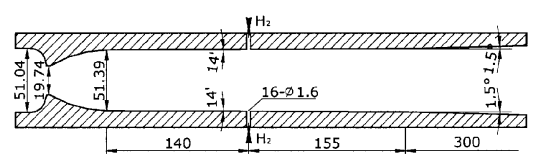

Combustor Model No.3

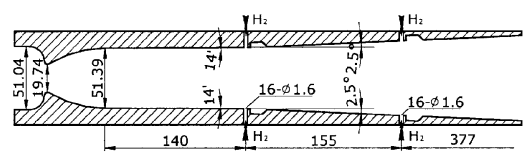

Combustor Model No.5
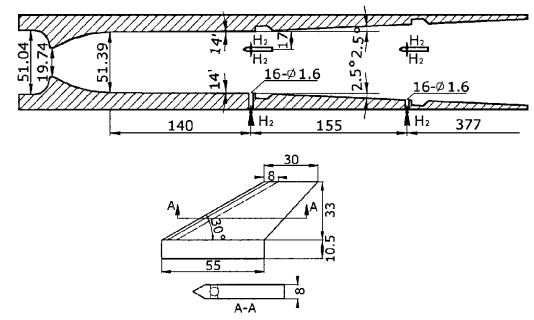

Combustor Model No.7

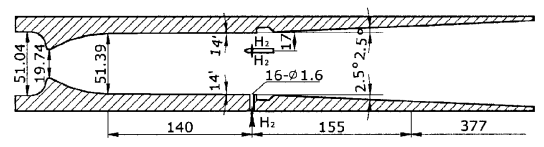

Combustor Model No.2

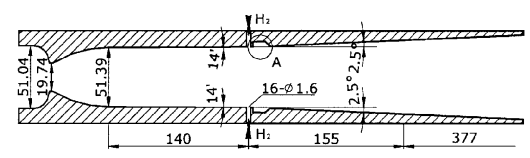

A

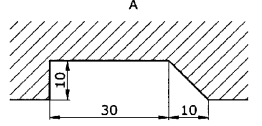

Combustor Model No.4

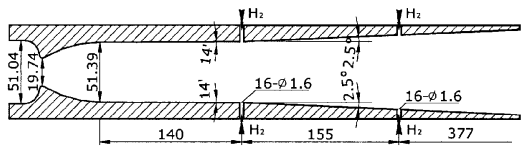

Combustor Model No.6

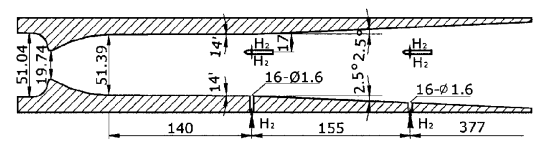

Combustor Model No. 8

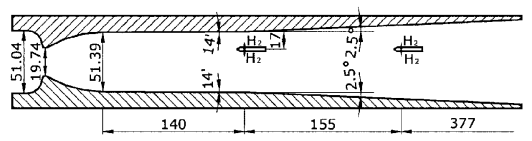

Figure 2. Schematic of eight model combustors investigated.

\section{Configuration Descriptions of Eight Model Combustors}

Mode/No.1. There was a single station of wall normal injection located at $140 \mathrm{~mm}$ downstream of the nozzle exit. The normal injection station consisted of multiple-orifice along the top and bottom walls. There was a row of 16 orifices on each wall. Model Combustor 1 was composed of 
two sections. The first section was $295 \mathrm{~mm}$ long with a boundary layer correction angle of $\sim 0.5$-degree, while the second section was of $300 \mathrm{~mm}$ in length with a half expansion angle of 1.5 degrees.

Model No. 2. Similar to Model Combustor 1, except (1) the first section was shortened to $140 \mathrm{~mm}$ long, and the second section was $532 \mathrm{~mm}$ in length with a half expansion angle of 2.5 degrees; and (2) there was a cavity following each wall injection system.

Model No. 3. Similar to Model Combustor 2, except (1) there were two stations of wall normal injection located at 140 and $295 \mathrm{~mm}$ downstream of the nozzle exit, respectively; and (2) there were two cavity pairs respectively located at $150 \mathrm{~mm}$ and $310 \mathrm{~mm}$ downstream of the nozzle.

Model No. 4. Similar to Model Combustor 3, except there was no cavity.

ModelNo.5. Similar to Model Combustor 3, except there were two backswept strut injectors replacing the two rows of wall normal injection orifices along the top wall. The strut was centered at the location of the wall injection system and off the combustor centerline by $8.5 \mathrm{~mm}$.

ModelNo. 6. Similar to Model Combustor 5, except there was no cavity.

Model No. 7. Similar to Model Combustor 2, except there was a strut injector replacing the wall injector on the top wall, which was located at $140 \mathrm{~mm}$ downstream of the nozzle exit.

Model No. 8. Similar to Model Combustor 6, except there was no wall injection system.

\section{Pressure Measurements}

The stagnation pressure of vitiated air in the heater was measured by using a CBY-21S (Zhong Hang Machinery and Electron Technology Corporation) $0-6 \mathrm{MPa}$ pressure sensor, with experimental error being within $2 \%$. Moreover, the total pressure at the exit of the model combustor was measured using water-cooled Pitot probes (cf. Figure 1). The associated pressure sensor employed was a Sensym 19CIU300 
$0 \sim 1.5 \mathrm{MPa}$. The experimental error in the total pressue measurement was within $3 \%$.

Three rows of pressure ports along each of the top and bottom walls were arranged to measure the static pressure distribution inside the combustor. For each row, there were 16 pressure ports aligned in the axial direction. In order to obtain a mean, axial pressure distribution, pressure data were averaged at every cross section. Motorala MPX2200 $0 \sim 0.4 \mathrm{MPa}$ pressure sensors were used to detect the static pressure signal. The uncertainty associated with the static pressure measurement was estimated to be within $2 \%$.

\section{Stagnation Temperature Measurements}

Stagnation temperature, $T_{t}$, was measured by B-type thermocouples with corrections for radiation, conduction, and thermal inertia, which was further compared with the computed value based on the measured stagnation pressure and reactant flow rates. The experimental error in the stagnation temperature measurement was within $3 \%$ for $T_{t}<2000 \mathrm{~K}$.

\section{RESULTS AND DISCUSSION}

\section{Experimental Procedures}

Performance of the heater, which produced the high temperature vitiated air, has been described in $\mathrm{Yu}$ et al. (1996). A typical experimental duration was 4-7 seconds. The major gases (air, $\mathrm{O}_{2}, \mathrm{H}_{2}$ ) were released one second after a spark ignited the pilot hydrogen/air mixture. It generally took $2 \mathrm{~s}$ to achieve the required temperature and pressure in the heater, as shown by the time variations of the stagnation pressure $\left(\mathrm{P}_{\mathrm{t}}\right)$ and the stagnation temperature $\left(T_{t}\right)$ in Figure 3. Figure 4 plots the static pressure distribution within the combustor as a function of time. It is seen that the supersonic flow field reached steady-state within 2.5 seconds. Once the Mach 2.5 air flow was established, hydrogen was injected at sonic speed into the combustor. If ignition was achieved and combustion was subsequently sustained, the static pressure in the combustor increased immediately, as demonstrated in Figure 4. Figure 4 further shows that after approximately $3.85 \mathrm{~s}$ the pressure distribution was stable and the flame was stabilized. It is further noted that, while the combustor walls were not specially cooled, at various conditions the wall 


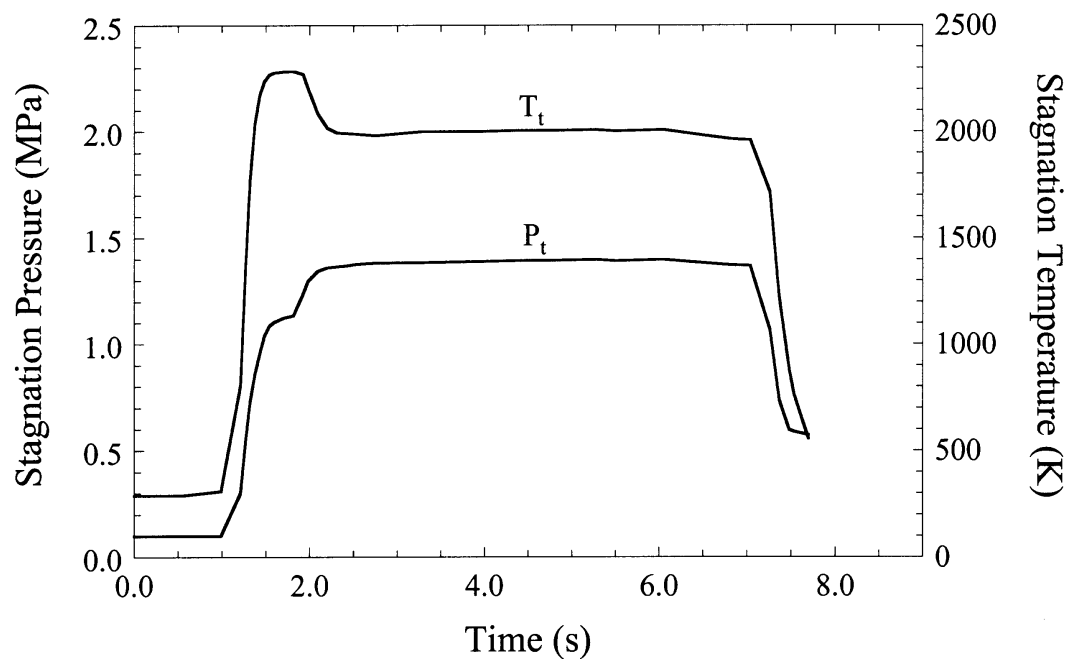

Figure 3. Typical time variations of the stagnation pressure $\left(\mathrm{P}_{t}\right)$ and stagnation temperature $\left(T_{t}\right)$ produced by the heater facility.

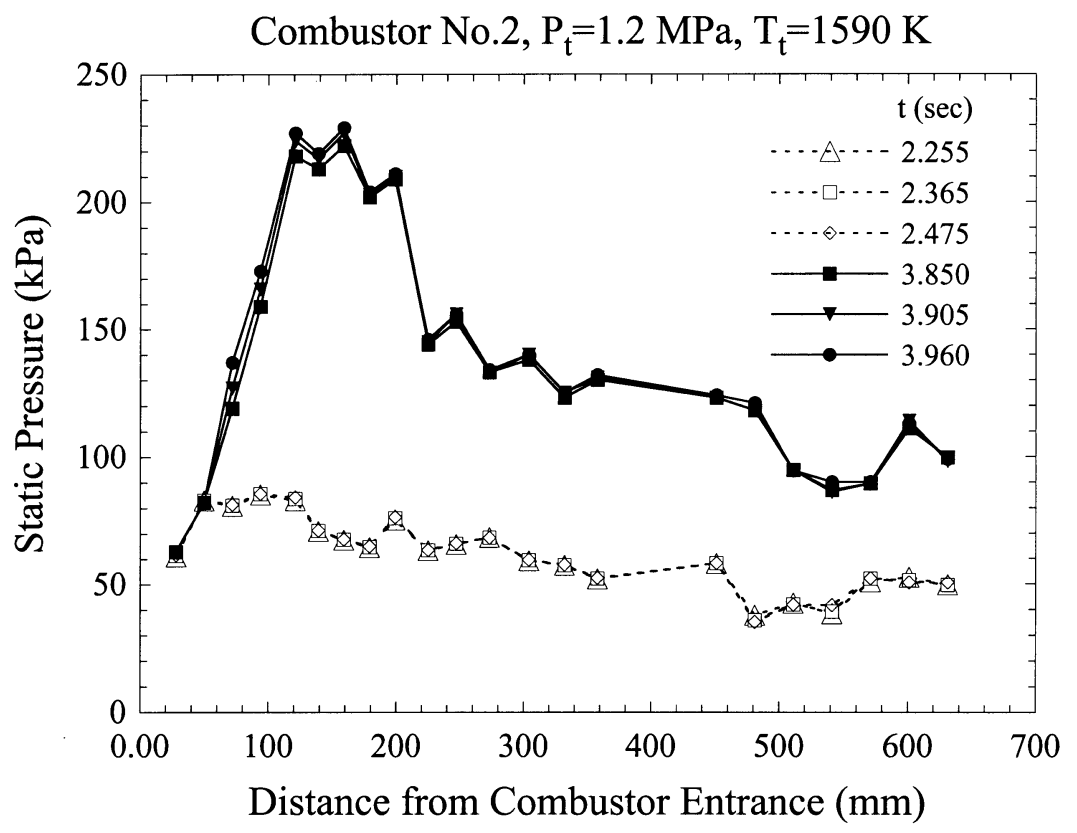

Figure 4. Typical axial distributions of the static pressure within Model Combustor 2 at various moments. The stagnation conditions were $\mathrm{P}_{\mathrm{t}}=1.2 \mathrm{MPa}$ and $\mathrm{T}_{\mathrm{t}}=1590 \mathrm{~K}$. 
temperature was found to range between $325 \mathrm{~K}$ and $400 \mathrm{~K}$, even after stable combustion was established.

A series of experiments using various model combustors were conducted under stagnation temperatures varying from $1200 \mathrm{~K}$ to $2000 \mathrm{~K}$ and stagnation pressures ranging from 1 to $1.4 \mathrm{MPa}$. The global equivalence ratio $(\phi)$ varies from lean to rich. However, it should be noted that in the present setup a larger global equivalence ratio implies a higher momentum ratio between the hydrogen jet and the air stream. This is because for a given size of fuel injector, the flow rate, as well as the momentum of $\mathrm{H}_{2}$ injection, were increased through the increase in the plenum pressure.

\section{Thermal Occlusion}

Figure 5 compares the static pressure distributions in the axial direction, after stable combustion was sustained, for Model Combustor 1 with various global equivalence ratios. The stagnation pressure and stagnation temperature were kept constant around $1.3 \mathrm{MPa}$ and $1900 \mathrm{~K}$, respectively. The dashed line, denoting the corresponding supersonic flow field established before the fuel injection, is also plotted as a reference. Since heat release generally increases with increasing global equivalence ratio and the area increase in the combustor is fixed for a given expansion angle, it is expected that beyond a critical equivalence ratio thermal occlusion could result from the increasing heat addition to a supersonic stream. Indeed, Figure 5 shows that the static pressure at the first measurable location downstream of the nozzle increased with increasing global equivalence ratio. The results indicate that the larger the equivalence ratio, the higher the static pressure at the combustor entrance, the higher tendency thereby leading to thermal choking. We nonetheless have to emphasize that further data analysis is needed in order to confirm whether the combustor was actually thermally choked or not. A one-dimensional model was thus employed to serve such a need, which will be demonstrated in a later section.

To further illustrate the effect of the area increase in the combustor, Figure 6 compares the static pressure distributions in Model Combustors 1 and 2 for a given 1.3 MPa stagnation pressure and a $1900 \mathrm{~K}$ stagnation temperature. As a reminder, the major differences between the above two model combustors include the combustor length, the combustor expansion angle, and the existence of cavities. It is first noted that for the given 


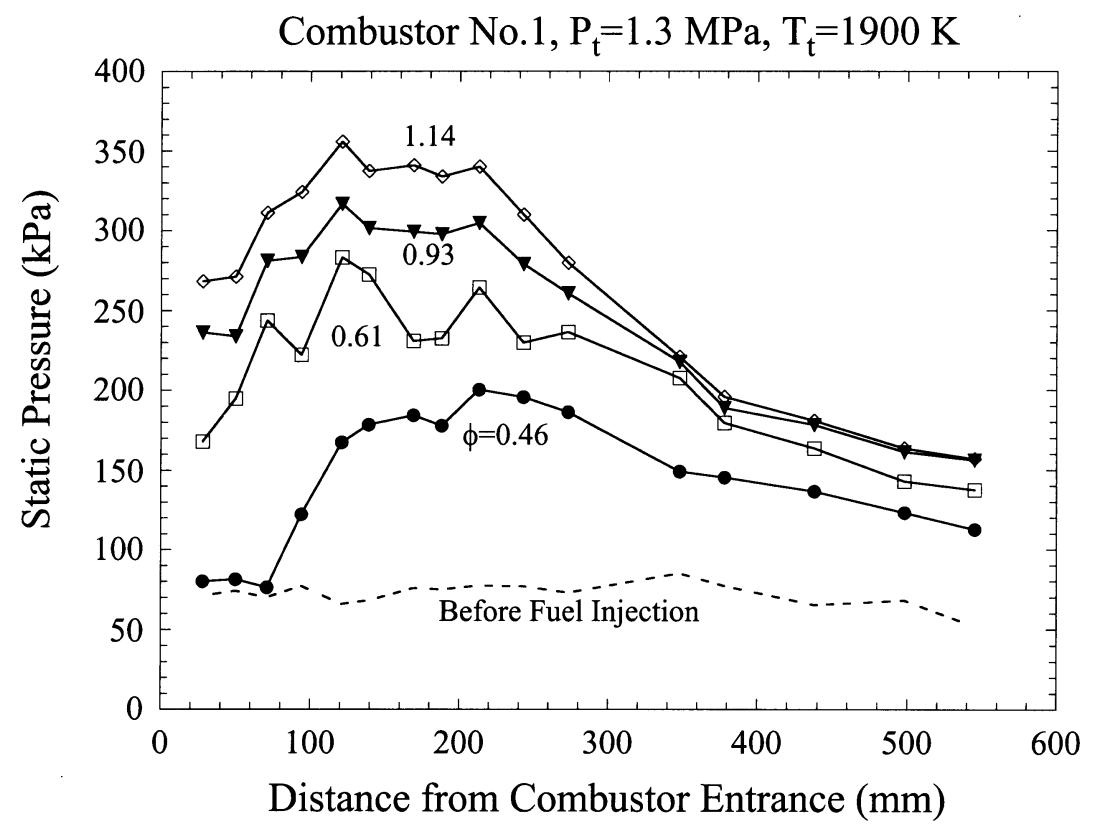

Figure 5. Variations of static pressure profiles in the axial direction subjected to various global equivalence ratios, for Model Combustor 1. The stagnation conditions were $P_{t}=1.3 \mathrm{MPa}$ and $\mathrm{T}_{\mathrm{t}}=1900 \mathrm{~K}$. The dashed line corresponded to the static pressure profile before fuel injection.

stagnation conditions, the leanest global equivalence ratio leading to selfignition for Model Combustor 1 was smaller than that for Model Combustor 2. In addition, it was found that if there were no cavities for Model Combustor 2, self-ignition could only be achieved when the global equivalence ratio was greater than 0.90 , which was much higher than 0.70 for the case with cavities.

Furthermore, it is seen from Figure 6 that for Model Combustor 1 the static pressure first increased rapidly, then reached an isobaric plateau within the section of nearly constant area, and eventually decreased toward the combustor exit, owing to the significant expansion process in the second section. As a result, this pressure distribution can be approximated as a ladder-shaped profile. For Model Combustor 2, however, despite the initial increase in the static pressure, it decreased significantly toward the combustor exit immediately after reaching a peak pressure value. This is because in Model Combustor 2 the constant-area section was 


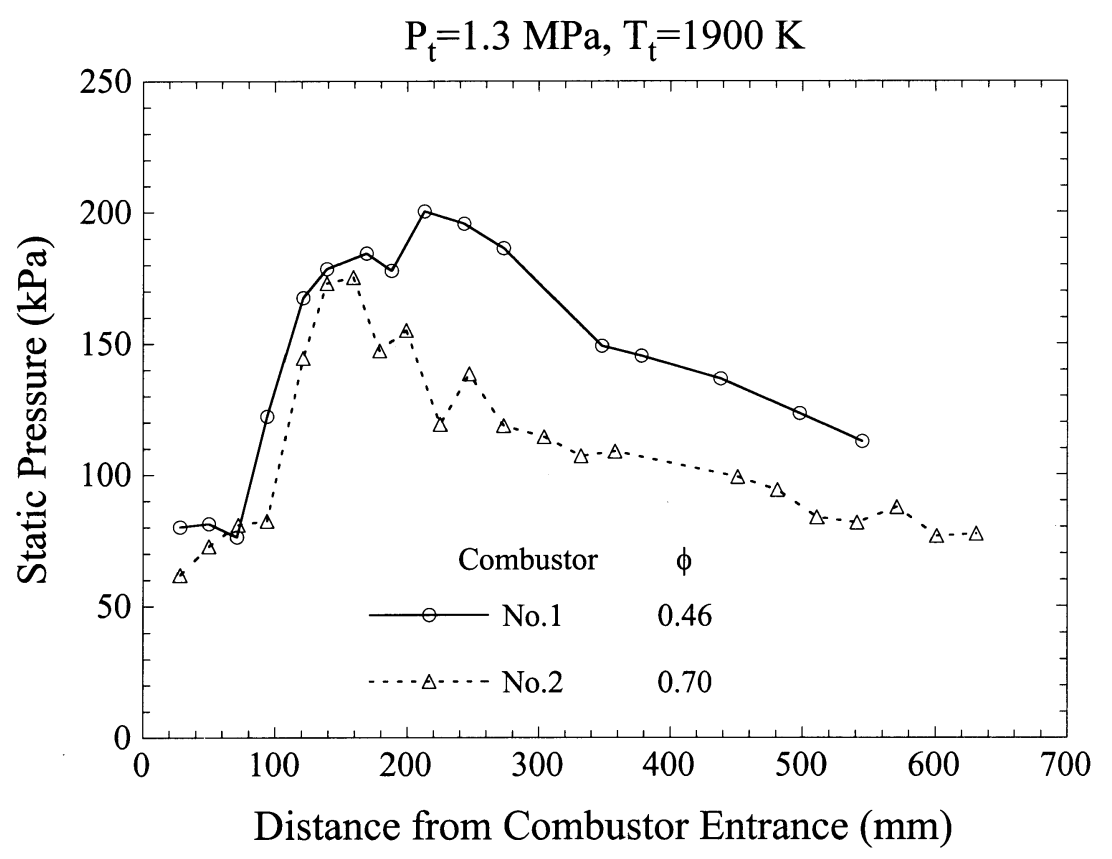

Figure 6. Comparison of static pressure profiles for Model Combustors 1 and 2. The stagnation conditions were $P_{t}=1.3 \mathrm{MPa}$ and $T_{t}=1900 \mathrm{~K}$.

shorter and the expansion angle was larger. While such a configuration as that in Model Combustor 2 could elude potential thermal choking, the accompanying penalty was the difficulty in self-ignition and flameholding.

\section{Effects of Cavity Flameholders}

Figure 7 compares the combustion characteristics for the wall-injection cases with and without cavities by plotting the static pressure profiles under various equivalence ratios. We note that for given stagnation conditions $\mathrm{P}_{\mathrm{t}}=1.3 \mathrm{MPa}$ and $\mathrm{T}_{\mathrm{t}}=1900 \mathrm{~K}$, the inclusion of cavities was seen to substantially facilitate self-ignition because of the smaller critical equivalence ratio required for the configuration with cavities, namely Model Combustor 3.

Figure 8 further shows the effect of cavities on combustor performance for the cases with combined fuel injection through both walls and struts, for a stagnation pressure of $1.3 \mathrm{MPa}$ and a stagnation temperature of $1900 \mathrm{~K}$. The promotion of self-ignition and flame stabilization with the 


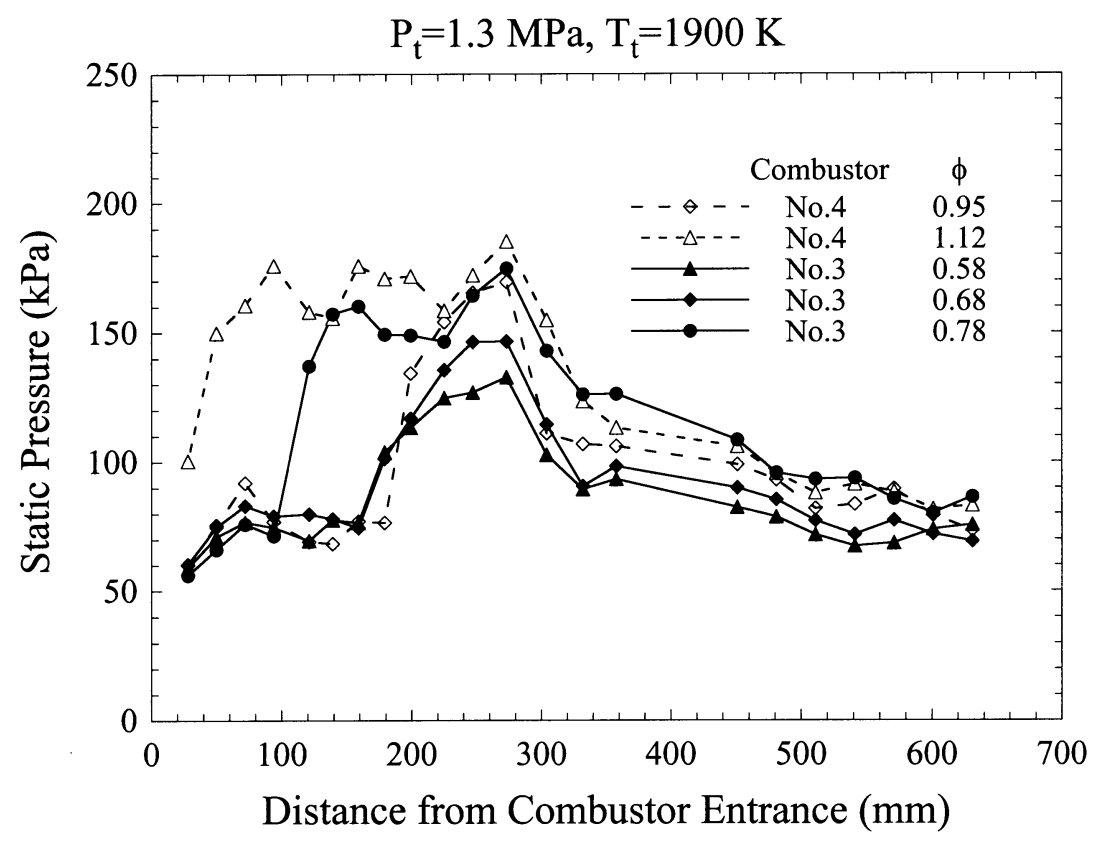

Figure 7. Comparison of static pressure profiles for Model Combustors 3 and 4, demonstrating the effects of cavity flameholder. The stagnation conditions were $\mathrm{P}_{\mathrm{t}}=1.3 \mathrm{MPa}$ and $\mathrm{T}_{\mathrm{t}}=1900 \mathrm{~K}$.

aid of cavities was evident in that the required equivalence ratio for stable combustion in Model Combustor 5 was much smaller. In addition, comparing Model Combustor 3 in Figure 7 and Model Combustor 5 in Figure 8, it is seen that the use of the strut injection further reduced the critical equivalence ratio leading to self-ignition.

\section{Effects of In-Stream Strut}

In addition to the promotion of self-ignition, the use of in-stream strut can also affect the degree of thermal occlusion. We first compare the cases with two struts in tandem and with a single strut, namely Model Combustor 5 versus Model Combustor 7, as shown in Figure 9. For given stagnation conditions, $\mathrm{P}_{\mathrm{t}}=1.3 \mathrm{MPa}$ and $\mathrm{T}_{\mathrm{t}}=1900 \mathrm{~K}$, and similar global equivalence ratios, the single-strut configuration (Combustor 7) was shown to have a shorter plateau in terms of static pressure distribution. This implies that the single-strut design would have a 


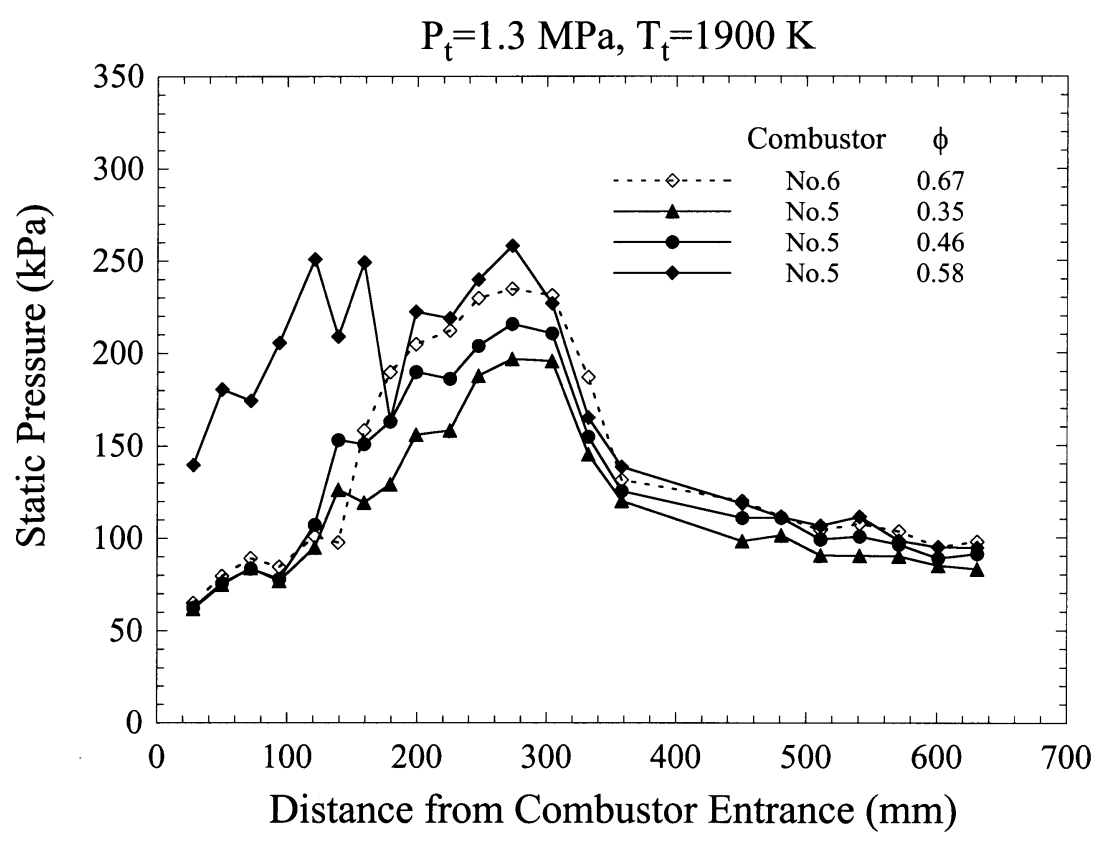

Figure 8. Comparison of static pressure profiles for Model Combustors 5 and 6 , demonstrating the effects of cavity flameholder. The stagnation conditions were $P_{t}=1.3 \mathrm{MPa}$ and $\mathrm{T}_{\mathrm{t}}=1900 \mathrm{~K}$.

higher tendency to thermal choking since the heat release was less distributed.

In order to further demonstrate the tendency to thermal choking with and without struts, we next compare Model Combustors 3 and 5 . Figure 10 plots the spatially resolved profiles of static pressure with various global equivalence ratios and stagnation temperatures, for Model Combustor 3 with a fixed stagnation pressure of $1.3 \mathrm{MPa}$. It is of interest to note that the stagnation temperature required to achieve self-ignition and stable combustion could be as low as $1150 \mathrm{~K}$, even with normal injections only. Similar to the discussion of Figure 5, the back pressure near the combustor entrance increased as the equivalence ratio was increased and thermal occlusion was evident when the equivalence ratio was greater than 0.80 . Figure 11 is the counterpart plot for Model Combustor 5. With the addition of the strut injectors, although the lowest stagnation temperature leading to self-ignition was comparable with that of Model Combustor 3, adverse pressure gradient existed for all 


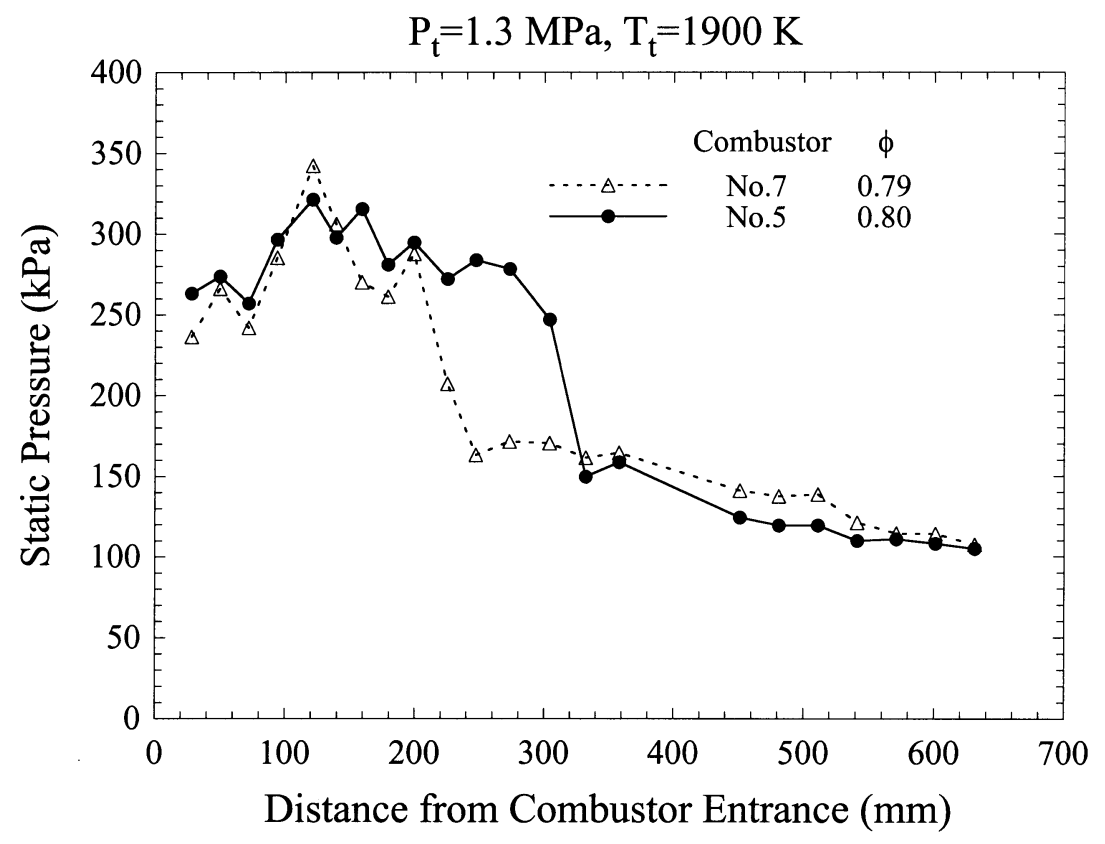

Figure 9. Comparison of static pressure profiles for Model Combustors 5 and 7, demonstrating the effects of in-stream strut. The stagnation conditions were $\mathrm{P}_{\mathrm{t}}=1.3 \mathrm{MPa}$ and $\mathrm{T}_{\mathrm{t}}=1900 \mathrm{~K}$.

cases. Analysis using a one-dimensional model (see Appendix) demonstrates that Model Combustor 5 was unconditionally thermally choked as soon as stable combustion was sustained.

\section{Analysis of One-Dimensional Model}

Figure 12 shows typical results yielded using a one-dimensional model, described in the Appendix, for Model Combustor 3. Based on the measured static pressures, denoted by symbols, the pressure distribution inside the combustor was first fitted, and subsequently used as an input to the one-dimensional model. Flow variables and thermophysical properties of interest, including the Mach number $M$, static pressure $P / P_{2}$, static temperature $T / T_{2}$, total pressure $P_{t} / P_{t 2}$, and core area $A / A_{2}$, can then be computed following the procedure outlined in the Appendix. Also note that the subscript 2 denotes the combustor entrance (cf. Figure A1), $P_{t 2}=10.8 \mathrm{MPa}, P_{2}=62 \mathrm{kPa}, T_{t 2}=1820 \mathrm{~K}$, 


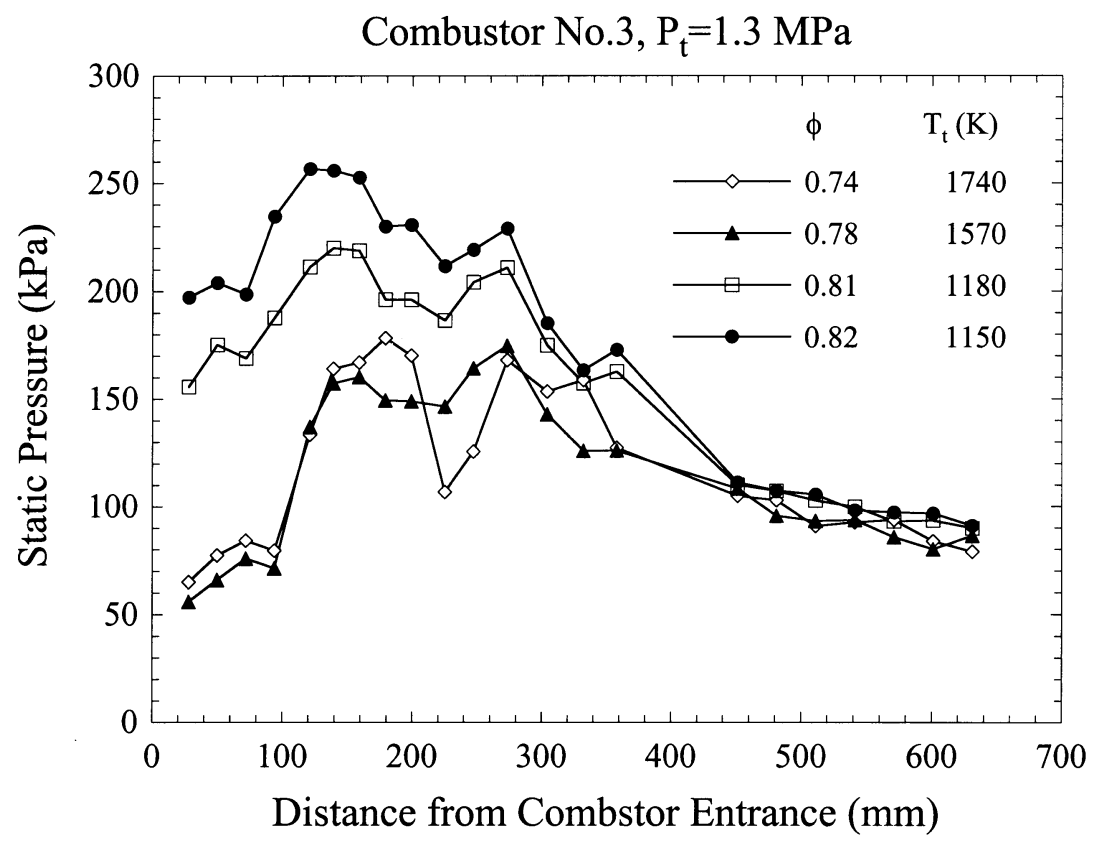

Figure 10. Comparison of static pressure profiles for Model Combustor 3, at various stagnation temperatures and global equivalence ratios. The stagnation pressure was fixed at $1.3 \mathrm{MPa}$.

and the global equivalence ratio was 0.72 . It is seen from Figure 12 that the heat addition rate (i.e., spatial gradient of $\mathrm{T}_{t}$ ) peaked at the downstream end of positive axial pressure gradient (station $d$ in Figure A1), at which isobaric heat release counterbalanced the relief effect of area expansion. After the starting point of area expansion (station $3^{\prime}$ in Figure A1), the effect of the area expansion overcame that due to the total temperature increase.

Furthermore, initially the static pressure rise due to adiabatic compression was accompanied by the reductions in Mach number, confined core area, and total pressure, in spite of the increase in the static temperature. The confined core area was seen to reach a minimum at station $d$, while the Mach number reaches a minimum at the beginning of negative pressure gradient (station $s$ in Figure A1). Since the minimal Mach number is greater than unity, the combustor was not thermally choked at the present experimental conditions. Beyond station $s$, the static pressure decreased toward the combustor exit. In addition, the 


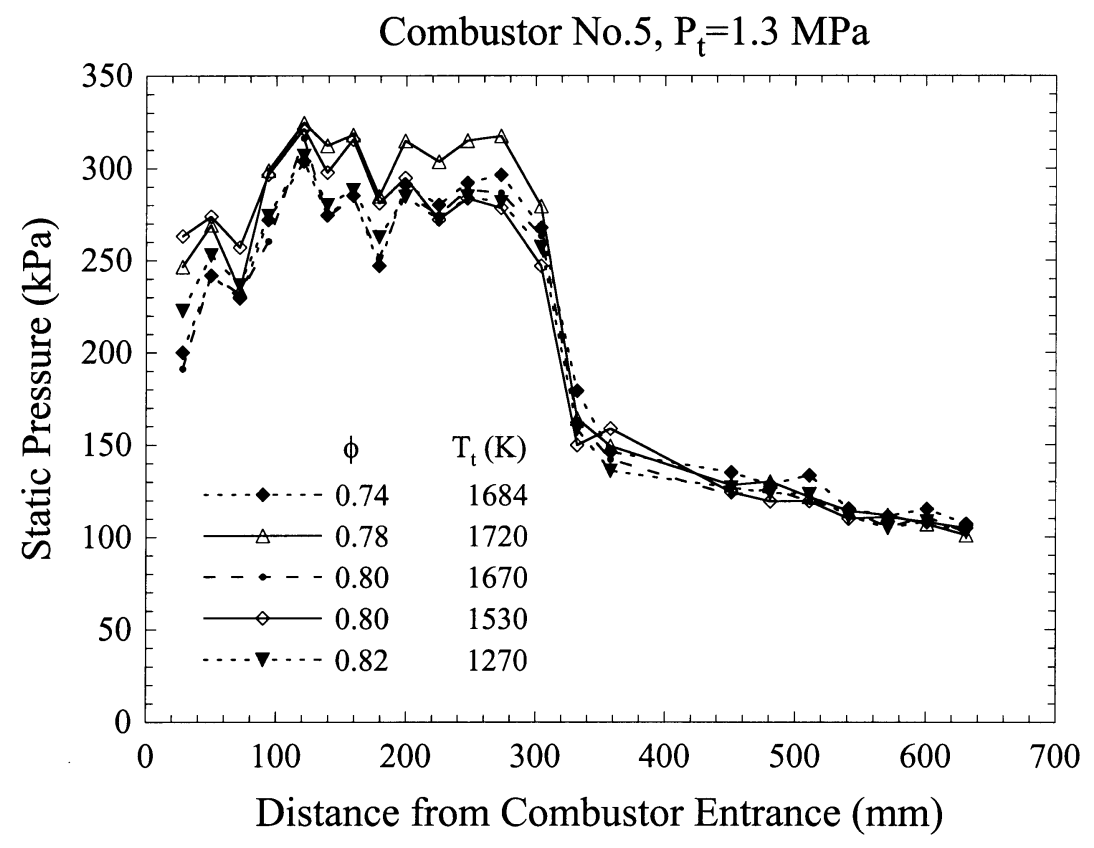

Figure 11. Comparison of static pressure profiles for Model Combustor 5, at various stagnation temperatures and global equivalence ratios. The stagnation pressure was fixed at 1.3 MPa.

Mach number, static temperature, and confined core area then gradually increased, accompanied by the reduction in total pressure.

To further demonstrate the usefulness of the rational function (Heiser and Pratt, 1994) defined in Equation (A11), a typical example is shown in Figure 13 by comparing the computed $T_{t} / T_{t 2}$ with the fitted rational function. It was found that the rational function with $\theta=8.10$, where $\theta$ is the empirical constant denoting the rate of heat release (cf. Appendix), can well represent the entire $T_{t} / T t_{2}$.

Table 1 summarizes the fitted values of $\theta$ for Model Combustors 2, 3, and 8. It is first noted that the values of $\theta$ ranged from 5 to 9 . Therefore, the rational function can be varied within this range for the preliminary estimate of combustor performance. Additionally, the general values of $\theta$ were respectively 6,5 , and 9 for Combustors 2,3 , and 8 . Since $\theta$ represents the rate of heat release, the results indicate that the addition of the strut injector (such as Combustor 8) seems to play an important role in promoting the heat release rate, and the two-station injection scheme 
Combustor No.3, $\phi=0.72, \mathrm{P}_{\mathrm{t} 2}=10.8 \mathrm{MPa}, \mathrm{T}_{\mathrm{t} 2}=1820 \mathrm{~K}, \mathrm{P}_{2}=62 \mathrm{kPa}$

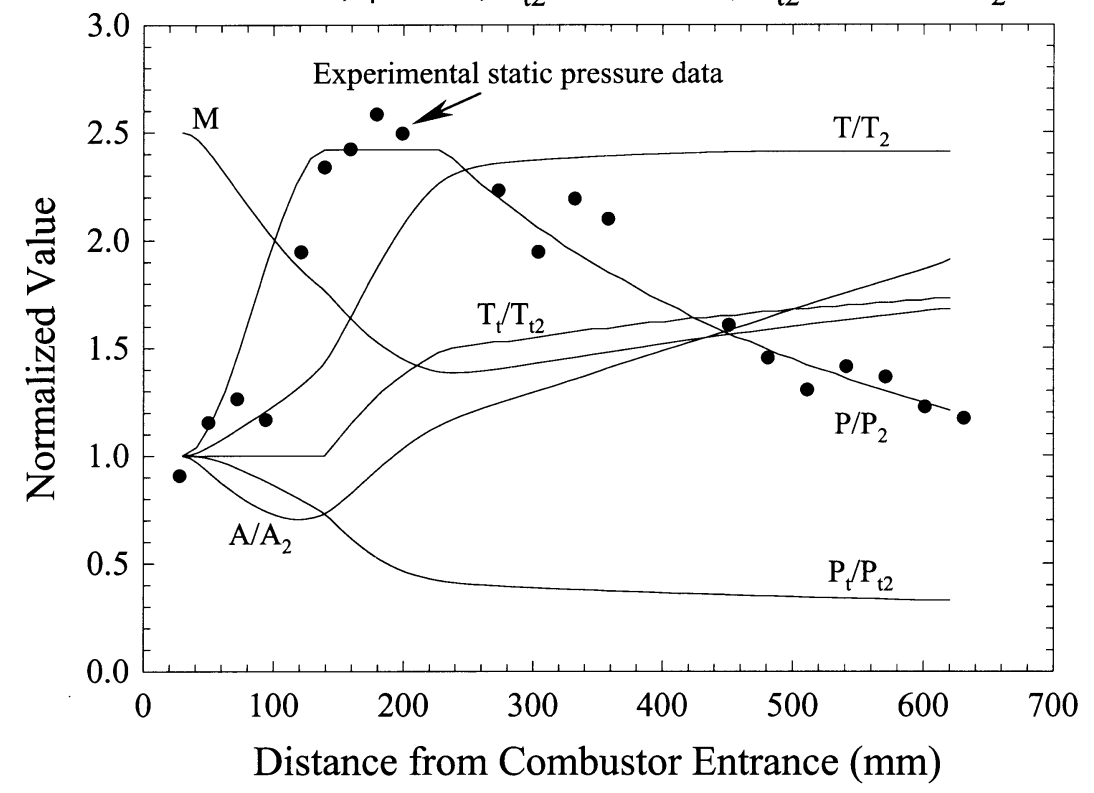

Figure 12. Comparison of experimental static pressure data and the calculated ones using one-dimensional model. Conditions: Model Combustor 3, $\phi=0.72, \mathrm{P}_{\mathrm{t} 2}=10.8 \mathrm{MPa}$, $\mathrm{T}_{\mathrm{t} 2}=1820 \mathrm{~K}$, and $\mathrm{P}_{2}=62 \mathrm{kPa}$.

(Combustor 3) may somewhat relieve the heat release rate as compared with the one-station injection case (Combustor 2).

In general, the approximate flow field obtained by using the present one-dimensional model is reasonable and consistent with the experimental observation. It, however, has to point out that the actual flow field is full of shocks, expansion waves, boundary layer separation, and their mutual interactions. Those complications were not considered in this one-dimensional model. In Table 1 we nevertheless apply the simplified model to compare the performance of various model combustors because it greatly facilitates data analyses.

\section{Comparison of Global Performance}

Typical measures of the global performance of a supersonic combustor include the distribution of static pressure, total pressure recovery, and combustion efficiency. The combustion efficiency is defined by the ratio 


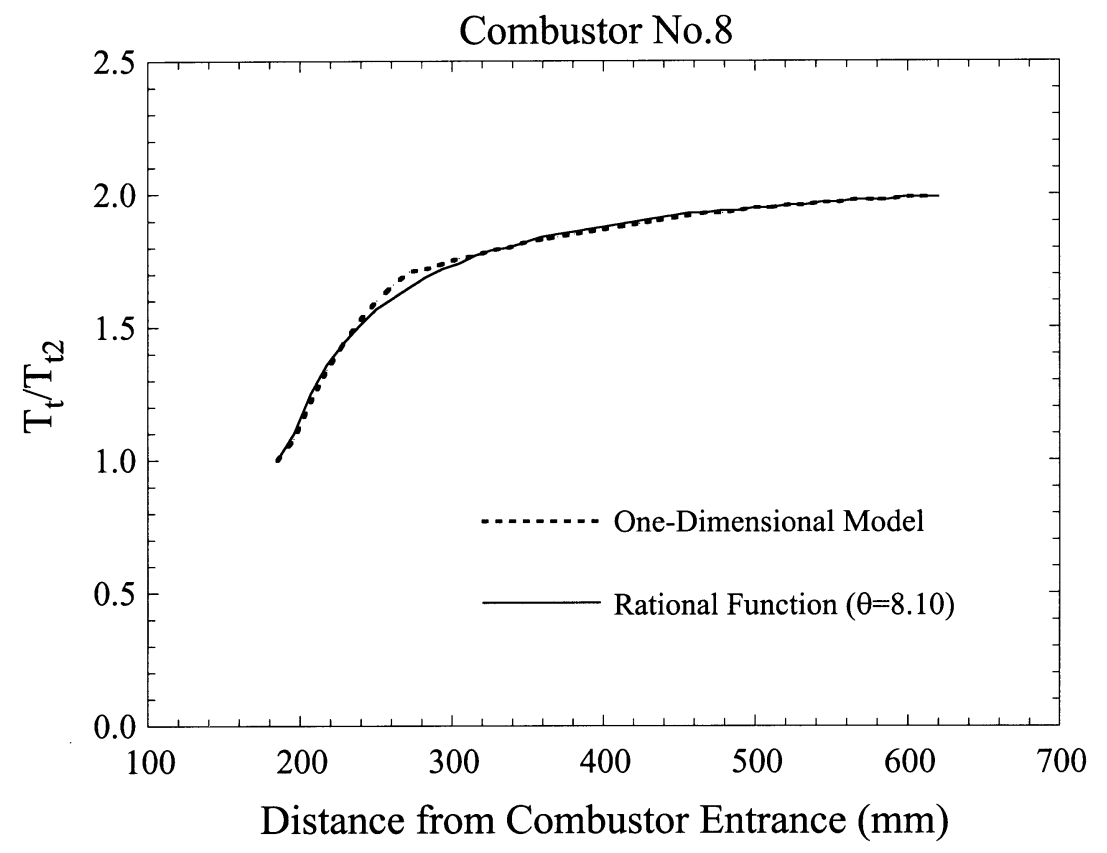

Figure 13. Comparison of the computed axial profile of stagnation temperature using onedimensional model and using rational function with $\theta=8.10$, for Model Combustor 8 .

Table 1. Summary of the fitted values of $\theta$ for Combustors 2, 3, and 8

\begin{tabular}{lccc}
\hline Combustor & $\phi$ & $\mathrm{T}_{\mathrm{t}}(\mathrm{K})$ & $\theta$ \\
\hline No. 2 & 0.51 & 1470 & 6.30 \\
& 0.62 & 1540 & 5.90 \\
& 0.70 & 1850 & 6.05 \\
No. 3 & 0.77 & 1820 & 6.35 \\
& 0.81 & 1636 & 5.74 \\
No. 8 & 0.90 & 1680 & 4.55 \\
& 0.99 & 1630 & 4.20 \\
& 0.78 & 1716 & 8.40 \\
& 0.84 & 1722 & 8.10 \\
& 0.89 & 1830 & 8.75 \\
& 0.91 & 1726 & 8.75 \\
& 1.13 & 1900 & 7.95 \\
\hline
\end{tabular}


of the static temperature increment between the exit and entrance of combustor to the temperature difference between the corresponding adiabatic flame temperature and the static temperature at the combustor entrance. Table 2 summarizes the comparisons of global combustor performance for Model Combustors 1, 2, 3, 4, and 8. In general, with increasing global equivalence ratio, the minimal Mach number, $M_{\min }$, decreased and approached unity, and eventually led to thermal choking.

It is also noted that the efficiency of Combustor 2 was about the same as that of Combustor 3. Additionally, for the configuration with strut injections only (Combustor 8), the values of $\mathbf{M}_{\min }$ were generally closer to unity than those of the cases with wall injections only. This implies that the use of strut injection is more susceptible to thermal choking because of the concentrated and rapid heat release. Moreover, among all the configurations investigated, although the one with strut injections yielded higher combustion efficiency, the corresponding total pressure loss was

Table 2. Comparisons of global performance for various model combustors

\begin{tabular}{|c|c|c|c|c|c|c|}
\hline Combustor & $\begin{array}{l}\text { Equivalence } \\
\text { ratio }\end{array}$ & $\begin{array}{c}\text { Total } \\
\text { temperature } \\
(\mathrm{K})\end{array}$ & $\begin{array}{c}\text { Combustion } \\
\text { efficiency }\end{array}$ & $\begin{array}{l}\text { Total } \\
\text { pressure } \\
\text { recovery }\end{array}$ & $\begin{array}{c}\text { Minimum } \\
\text { Mach } \\
\text { number }\end{array}$ & $\begin{array}{c}\text { Exit } \\
\text { Mach } \\
\text { number }\end{array}$ \\
\hline \multirow[t]{2}{*}{ No. 1} & 0.46 & 2000 & 0.87 & 0.44 & 1.34 & 1.76 \\
\hline & 0.61 & - & - & - & $<1.0$ & - \\
\hline \multirow[t]{4}{*}{ No. 2} & 0.51 & 1470 & 0.85 & 0.33 & 1.33 & 1.69 \\
\hline & 0.62 & 1540 & 0.84 & 0.33 & 1.25 & 1.66 \\
\hline & 0.70 & 1850 & 0.92 & 0.43 & 1.32 & 1.68 \\
\hline & 0.77 & 1820 & 0.97 & 0.41 & 1.16 & 1.64 \\
\hline \multirow[t]{5}{*}{ No. 3} & 0.58 & 1700 & 0.86 & - & 1.45 & 1.71 \\
\hline & 0.68 & 1800 & 0.82 & 0.51 & 1.34 & 1.76 \\
\hline & 0.81 & 1636 & 0.81 & 0.33 & 1.24 & 1.63 \\
\hline & 0.90 & 1680 & 0.94 & 0.31 & 1.18 & 1.53 \\
\hline & 0.99 & 1630 & 0.95 & 0.31 & 1.14 & 1.49 \\
\hline \multirow[t]{3}{*}{ No. 4} & 0.91 & 1810 & 0.71 & 0.44 & 1.36 & 1.75 \\
\hline & 0.95 & 1797 & 0.75 & 0.43 & 1.26 & 1.74 \\
\hline & 1.12 & 1800 & 0.89 & 0.45 & 1.21 & 1.61 \\
\hline \multirow[t]{6}{*}{ No. 8} & 0.78 & 1716 & 0.99 & 0.22 & 1.09 & 1.56 \\
\hline & 0.84 & 1722 & 0.99 & 0.23 & 1.07 & 1.55 \\
\hline & 0.89 & 1830 & 0.99 & 0.24 & 1.08 & 1.58 \\
\hline & 0.91 & 1726 & 0.98 & 0.22 & 1.07 & 1.57 \\
\hline & 1.10 & 1809 & 0.97 & 0.26 & 1.09 & 1.60 \\
\hline & 1.13 & 1900 & 0.99 & 0.26 & 1.02 & 1.58 \\
\hline
\end{tabular}


much larger then those of wall-injection cases. Therefore, the comparison suggested that configurations with wall injections alone are adequate in providing satisfactory combustor performance in terms of both combustor efficiency and total pressure recovery.

\section{SUMMARY}

A series of supersonic combustion experiments were systematically conducted using a wide variety of model combustors. There were eight different configurations, while the entry Mach number was kept constant at 2.5. Fuel injection schemes of interest included wall injection, strut injection, and their combination. Cavity flameholders were also integrated into the system as a comparison. Experimentally, stagnation temperatures varied from $1200 \mathrm{~K}$ to $2000 \mathrm{~K}$, stagnation pressures ranged from 1 to 1.4 MPa, and the global equivalence ratio covered the range from lean to rich. For all cases, the static pressure distribution in the axial direction and total pressure at the combustor exit were measured. Experimental data were further analyzed using a simplified one-dimensional model, which provides insights into the assessment of the model combustor performance as well as the identification of the optimal operation mode.

It was found that the static pressure at the combustor entry increased with increasing global equivalence ratio. Such an increase eventually led to thermal choking. A model combustor with shorter constant-area section and larger expansion angle has a reliving effect in terms of thermal occlusion. Cavity flameholders were seen to facilitate self-ignition characteristics and flame stabilization due to the fact that the critical equivalence ratio leading to stable combustion was substantially reduced with the use of cavities. Although the use of in-stream strut injectors promoted mixing and hence stable combustion, it was more susceptible to thermal choking. In addition, while model combustors with strut injectors tended to have high thermal efficiency, their total pressure recovery was poor.

The simplified one-dimensional model has been shown to be reasonable and insightful. The present study further demonstrated the usefulness of the rational function for the total temperature distribution. In particular, the empirical constant $\theta$, representing the rate of heat release, was found to range between 5 and 9 for various model combustors employed herein. As such, in the spirit of preliminary design one may systematically vary the rational function within its realistic range for the assessment of combustor performance. 


\section{REFERENCES}

Baurl, R.A., and Gruber, M.R. (1998) A study of recessed cavity flow-fields for supersonic combustion application. AIAA Paper 98-0938, American Institute of Aeronautics and Astronautics, Inc., Washington, DC.

Ben-Yakar, A., and Hanson, R.K. (1999) Supersonic combustion of cross-flow jets and the influence of cavity flame-holders. AIAA Paper 99-0484, American Institute of Aeronautics and Astronautics, Inc., Washington, DC.

Billig, F.S. (1967) Design of supersonic combustors based on pressure-area fields. Proc. Combust. Inst., 11, 755.

Billig, F.S. (1993) Research on supersonic combustion. Journal of Propulsion and Power, 9(4), 499.

Billig, F.S., Dugger, G.L., and Waltrup, P.J. (1972) Inlet-combustor interface problems in scramjet engine. Proceedings of the First International Symposium on Airbreathing Engines, June Marseilles, France.

Bushnell, D.M. (1994) Mixing and combustion issues in hypersonic air-breathing propulsion. In Buckmaster, J. (Ed.), Combustion in High-Speed Flows, Kluwer Academic Publishers, Norwell, MA.

Drummond, J.P. (1991) Mixing enhancement of reacting parallel fuel jets in a supersonic combustor. AIAA Paper 91-1914, American Institute of Aeronautics and Astronautics, Inc., Washington, DC.

Heiser, W.H., and Pratt, D.T. (1994) Hypersonic Airbreathing Propulsion. American Institute of Aeronautics and Astronautics, Inc., Washington, DC.

Li, J.G., Yu, G., Zhang, Y., Li, Y., and Qian, D.X. (1997) Experimental studies on self-ignition of hydrogen/air supersonic combustion. Journal of Propulsion and Power, 13(4), 538.

Marble, F.E. (1990) Shock enhancement and control of hypersonic mixing and combustion. AIAA Paper 90-1981, American Institute of Aeronautics and Astronautics, Inc., Washington, DC.

Shapiro, A.H. (1953) The Dynamics and Thermodynamics of Compressible fluid Flow. Ronald Press, New York.

Yu, G., Li, J.G., Zhao, J.R., and Yang, S.R. (1996) Experimental studies on $\mathrm{H}_{2}$ /air supersonic combustion. AIAA Paper 96-4512, American Institute of Aeronautics and Astronautics, Inc., Washington, DC.

Yu, G., Li, J.G., Qian, D.X., and Han, B. (1998) Hydrogen-air supersonic combustion study by strut injectors. AIAA Paper 98-3275, American Institute of Aeronautics and Astronautics, Inc., Washington, DC.

Yu, K., Wilson, K.J., Smith, R.A., and Schadow, K.C. (1998) Experimental investigation on dual-purpose cavity in supersonic reacting flows. AIAA Paper 98-0723, American Institute of Aeronautics and Astronautics, Inc., Washington, DC. 


\section{APPENDIX: PHYSICAL MODEL OF A SUPERSONIC COMBUSTOR}

As discussed earlier, the typical distribution of experimental static pressure can be approximated as a ladder-shaped profile, as sketched in Figure A1. Following the analysis of Heiser and Pratt (1994), the physical processes consist of adiabatic compression, heat addition at constant pressure, and heat addition with variable pressure. The stations $2,3,3^{\prime}$, and 4, respectively, designate the combustor entrance, the fuel injection location, the starting point of area expansion, and the combustor exit. Alternatively, the nearly constant area section $\left(2-3^{\prime}\right)$ can be considered as an extension of the isolator. Station $d$ denotes the downstream end of a positive axial pressure gradient, in which heat addition commences. It is further assumed that station $d$ is located in the constant area section. In addition, station $s$ denotes the beginning of negative pressure gradient.

In the original model of Heiser and Pratt (1994), it was assumed that the fuel injection location (station 3) coincides with the starting point of area expansion (station $3^{\prime}$ ), and hence combustion has to occur in the divergent section. However, the assumptions of Heiser and Pratt are too
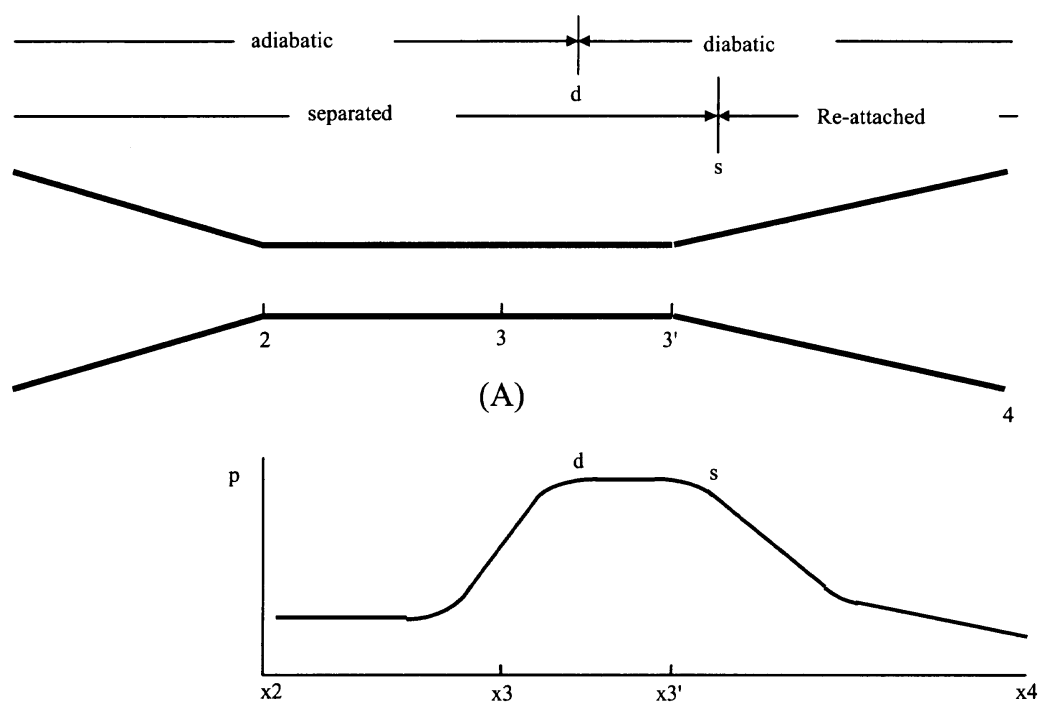

(B)

Figure A1. Sketch of one-dimensional model for experimental data analysis. (A) Designation of axial location. (B) Typical axial distribution of static pressure. 
restrictive and can be relaxed. As such, we have modified their model to account for the present combustor configurations. Moreover, we assumed that the initial pressure rise at the constant-area section is not directly due to the heat release, but rather is caused by the adiabatic compression of an oblique shock train. Consequently, the back pressure due to heat release within the combustor is matched by the adiabatic pressure increase from the pre-combustion shock train (Heiser and Pratt). Figure A1 also indicates that the static pressure is constant from $d$ to $s$ because the maximum pressure is transmitted upstream freely through the boundary layer separation region near the wall. It has to be noted that the location of station $s$ may occur within the constant area section, which was not considered in the original model of Heiser and Pratt. If the location of station $s$ is within the constant-area section, we have to assume that the flow reattaches at station $3^{\prime}$. From station $s$ to station 4 , the relieving effect due to area increase dominates over the effect of heat addition. Therefore, the static pressure starts to decrease throughout the remainder of combustor.

Based on the above-mentioned modifications from the one-dimensional model of Heiser and Pratt (1994), the combustor was divided into three sections, namely section $2-d$, section $d-s$, and section $s-4$. The system equations for each section and the procedure to close the problem are outlined as follows:

\section{Section 2 to $d$}

Recognizing that there is no heat exchange between the flow and the combustor wall and that the flow is assumed to be separated owing to the adiabatic compression of the oblique shock train, the flow Mach number, $M$, within the confined core, can then be calculated by solving the following algebraic equations (Heiser and Pratt, 1994):

$$
\begin{aligned}
& M=\left[\frac{\gamma^{2} M_{2}^{2}\left(1+\frac{\gamma-1}{2} M_{2}^{2}\right)}{\left(1+\gamma M_{2}^{2}-\frac{P}{P_{2}}\right)^{2}}-\left(\frac{\gamma-1}{2}\right)\right]^{\frac{1}{2}} \\
& \frac{A}{A_{2}}=\frac{1}{\gamma M^{2}}\left[\frac{P_{2}}{P}\left(1+\gamma M_{2}^{2}\right)-1\right] \\
& \frac{P}{P_{2}}=1+\left(\frac{P_{d}}{P_{2}}-1\right)(3-2 \chi) \chi^{2},
\end{aligned}
$$


where $\gamma$ is the specific heat ratio, $P$ the static pressure, and $A$ the confined core area. In addition, the experimental static pressure profile is curve fitted by a cubic polynomial according to Billig et al. (1972) in the normalized coordinate, $\chi$, defined as $\chi=\left(\mathrm{x}-\mathrm{x}_{2}\right) /\left(\mathrm{x}_{4}-\mathrm{x}_{2}\right)$.

\section{Station $d$ to $s$}

In this section the isobaric heat release takes place. Assuming the effects of wall friction, drag of internal strut injection, and mass addition due to the jet flow are negligible compared to the interaction between the axial variations of core area and of total temperature, the governing equations for the axial variation of Mach number can be written as (Heiser and Pratt, 1994):

$$
\frac{d M}{d \chi}=M\left(\frac{1+\frac{\gamma-1}{2} M^{2}}{1-M^{2}}\right)\left[-\left(\frac{d A}{A d \chi}\right)+\frac{\left(1+\gamma M^{2}\right)}{2}\left(\frac{d T_{t}}{T_{t} d \chi}\right)\right] .
$$

Equation (A4) is solved together with the following integral relations of Shapirio (1953):

$$
\begin{aligned}
& T=T_{2} \frac{T_{t}}{T_{t 2}}\left(\frac{1+\frac{\gamma-1}{2} M_{2}^{2}}{1+\frac{\gamma-1}{2} M^{2}}\right) \\
& P=P_{2} \frac{A_{2}}{A} \frac{M_{2}}{M} \sqrt{\frac{T}{T_{2}}} \\
& P_{t}=P_{t 2} \frac{P}{P_{2}}\left(\frac{T_{2}}{T} \frac{T_{t}}{T_{t 2}}\right)^{\frac{\gamma}{\gamma-1}} .
\end{aligned}
$$

Moreover, the core area of the flow, $A(\chi)$, is assumed to vary smoothly and reattach to the combustor wall at station $s$. As a result, $A(\chi)$ can be curve fitted with the known area values at station $2, d, s$, and 4 by a fourth-order polynomial. Representing $d T_{t} / d \chi$ in terms of $d A / d \chi, d P / d \chi$, $d M / d \chi$, and $M$, Equation (A4) can be rewritten as:

$$
\frac{d M}{d \chi}=\frac{\left(1+\gamma M^{2}\right) \frac{1}{P} \frac{d P}{d \chi}+\gamma M^{2} \frac{1}{A} \frac{d A}{d \chi}}{\frac{1-M^{2}}{M\left(1+\frac{\gamma-1}{2} M^{2}\right)}-\frac{\left(1+\gamma M^{2}\right)}{2}\left(\frac{2}{M}+\frac{(\gamma-1) M}{1+\frac{\gamma-1}{2} M^{2}}\right)} .
$$


Furthermore, since $d P / d \chi=0$ in this section, Eq. (A8) can be solved by a fourth-order Rung-Kutta method.

\section{Section $s$ to 4}

Heat release takes place with variable pressure in this section. Billig (1967) and Billig et al. (1972) recommended that such a combustion process is polytropic, and hence can be expressed as $P A^{n}=$ constant, where the exponent $n$ is determined by the pressure data within this interval as:

$n=-\frac{\ln P_{S}-\ln P_{4}}{\ln A_{s}-\ln A_{4}}$

Thus, the axial variation of pressure can be expressed as:

$\frac{d P}{d \chi}=-n P_{4} A_{4}^{n} \frac{1}{A^{n+1}} \frac{d A}{d \chi}$.

Again, the Mach number of the flow is obtained via Eq. (A8), with $d P / d \chi$ given by Eqs. (A9) and (A10).

\section{Rational Function}

In the above model, $A(\chi)$ is prescribed a priori, while $T_{t}(\chi)$, as well as the axial total temperature gradient $d T_{t} / d \chi$, is determined a posteriori. This is because the former, $A(\chi)$, may be given by design. On the other hand, $T_{t}(\chi)$ and $d T_{t} / d \chi$ depend on the burning rate, which in turn has to be determined by mixing processes and finite-rate chemical kinetics. For supersonic combustion, however, chemical heat release generally peaks at onset and then relaxes asymptotically toward the chemical equilibrium. As a result, $d T_{t} / d \chi$ is typically maximized shortly after ignition and decreases monotonically toward the combustion exit. Thus, if $T_{t}(\chi)$ can be reasonably represented by a rational function, it would substantially expedite the data reduction. A useful representation of the total temperature in nondimensional form has been suggested and given by Heiser and Pratt (1994):

$$
\tau(\chi)=1+\left(\tau_{b}-1\right)\left[\frac{\theta \chi}{1+(\theta-1) \chi}\right]
$$


where $\tau(\chi)=T_{t}(\chi) / T_{t 2}, \tau_{b}=T_{t 4} / T_{t 2}$, and $\theta$ is the empirical constant denoting the rate of heat release $(\theta \geq 1)$. With increasing $\theta$, the rise of $T_{t}$ is steeper. We have demonstrated in Figure 13 that the rational function can well represent the computed $T_{t}$, with an adequate choice of $\theta$. As such, for the purpose of preliminary design, one can explore the effects of various fuel injection and mixing strategies on supersonic combustor performance by systematically varying the rational function within its realistic range. 